\title{
Adaptation and major chromosomal changes in populations of Saccharomyces cerevisiae
}

\author{
Julian Adams, S. Puskas-Rozsa, J. Simlar, and C. M. Wilke \\ Department of Biology, University of Michigan, Ann Arbor, MI 48109, USA \\ Received December 17, 1991/February 10, 1992
}

\begin{abstract}
Summary. Thirteen independent populations of Saccharomyces cerevisiae (nine haploid and four diploid) were maintained in continuous culture for up to approximately 1000 generations, with growth limited by the concentration of organic phosphates in medium buffered at $\mathrm{pH}$ 6. Analysis of clones isolated from these populations showed that a number (17) of large-scale chromosomallength variants and rearrangements were present in the populations at their termination. Nine of the 16 yeast chromosomes were involved in such changes. Few of the changes could be explained by copy-number increases in the structural loci for acid phosphatase. Several considerations concerning the nature and frequency of the chromosome-length variants observed lead us to conclude that they are selectively advantageous.
\end{abstract}

Key words: Chromosome length variants - Adaptation Yeast - Continuous culture

\section{Introduction}

The genomes of prokaryotes appear to be much more labile (Krawiec and Riley 1990) than those of higher eukaryotes (e.g., O'Brien, Seuanez and Womack 1988). Duplications, sometimes involving large sections of the genome, occur at a high frequency in Salmonella and other prokaryotes (Krawiec and Riley 1990; Petes and Hill 1988), and it has been suggested that large-scale genomic changes represent an important mechanism of adaptation in such organisms (Anderson and Roth 1977; Sonti and Roth 1989). Genome rearragements caused by inversions and translocations are also seen frequently in prokaryote populations (Krawiec and Riley 1990) and may be important agents of adaptive change (Ornston et al. 1990). Less is known of the evolutionary role that deletions may play, though comparison of the genomes of Escherichia coli and Salmonella typhimurium suggest

Offprint requests to: $\mathrm{J}$. Adams that large deletions may have been significant factors in the evolutionary divergence of these two species (Riley 1984).

Surprisingly little is known of the role that large-scale genomic rearrangements play in evolution and adaptation in yeast populations, though strain-specific differences in chromosome size are known to exist (Link and Olson 1991). There is also some evidence that industrial populations of baker's yeast undergo radical changes in their genomic structure (including changes in ploidy level and chromosome loss (S. Fogel personal communication). In this paper we describe large-scale chromosomal rearragements that have occurred in populations of haploid and diploid strains of Saccharomyces cerevisiae evolving in organic-phosphate-limited environments for approximately $700-1000$ generations. We show that: (1) adaptation is frequently accompanied by large-scale duplications of the genome, (2) large deletions also occur but are less frequent and (3) that some populations have developed polymorphisms for chromosome length.

\section{Materials and methods}

Strains. The populations were initiated with either the haploid strain $\mathrm{CP} 1 \mathrm{AB}-1 \mathrm{~A}$, its diploid parent strain CP1AB (Paquin and Adams 1982), or with strain PO43-283B. This last strain contains a duplication of the right arm of chromosome II, including the acidphosphatase loci $\mathrm{PHO} 3$ and $\mathrm{PHO5}$, translocated to chromosome XVI (S. Puskas-Rozsa and J. Adams, unpublished results), and therefore carries two copies of PHO5-1, the wild-type allele of PHO5. The left terminus of the duplicated region of chromosome II was mapped to a position between PHO5 and TSM134, no more than $4 \mathrm{cM}$ to the left of PHO5 (Hansche et al. 1978). Strain PO43$283 \mathrm{~B}$ was constructed, by conventional genetic procedures, from strains 507 ( $\alpha$ mating type) and 512 (a mating type) which carry pho5, a null allele of PHOS on chromosome II, and also an allele of PHO5 conferring high acid-phosphatase activity on the duplicated region (Hansche et al. 1978). Strains 507 and 512 (Hansche et al. 1978) were crossed and the resulting diploid, A225, sporulated. Rare recombination events between chromosome II and the translocated region result in the production of ascospores carrying the null allele (pho5) on both chromosome II and the translocated region. Such recombinants were identified from the analysis of 
dissected asci which showed a 3:1 segregation ratio for acid-phosphatase activity $(+:-)$. Presence or absence of inducible acidphosphatase activity was determined by plate assay as described by Hansche et al. (1978). An acid-phosphatase negative strain carrying the duplication (A225-1A), identified in this way, was then crossed to strain $\mathrm{CP} 1 \mathrm{AB}-1 \mathrm{~A}$, and the resulting diploid sporulated. A similar analysis of segregation ratios for acid-phosphatase activity allowed the identification of strain PO43-283B, carrying the wild-type allele for PHO5, derived from CP1AB-1A, on both chromosome II and on the duplicated/translocated region of chromosome II.

Media, growth and sampling. Batch cultures were grown at $30^{\circ} \mathrm{C}$ in a gyratory shaker at $150-200$ gyrations/min. Continuous cultures were operated as chemostats and maintained at $30^{\circ} \mathrm{C}$ in culture vessels between 150 and $350 \mathrm{ml}$ in volume. Dilution rates in the continuous cultures were $0.17 \mathrm{~h}^{-1}$, equivalent to a cell generation time of approximately $4.1 \mathrm{~h}$. The defined organic-phosphate-limited medium buffered at pH6, described by Adams and Hansche (1974), was used with the following modifications; the major salts (that is, the five salts added in concentrations $\geq 1 \mathrm{mM}$ ) were used at $1.5 \times$ the concentration described, glucose concentration was $0.8 \%$ $(\mathrm{w} / \mathrm{v})$, and organic phosphate concentration was $0.2 \mathrm{mM}$ of $\mathrm{PO}_{4}$ The organic phosphates employed were phosphoglyceric acid (PGA), $\beta$-glycerol phosphate ( $\beta \mathrm{GP}$ ), glucose-1-phosphate (G1P), glucose-6-phosphate (G6P) and uridine-5'-monophosphate (UMP), all obtained from the Sigma Chemical Co., St. Louis, MO, Glucose, vitamins and the organic phosphates were filter-sterilized using a "Sterivex GS" filter (Millipore Corp., Bedford, MA), and added to the medium after autoclaving. Preliminary experiments demonstrated that the cultures were indeed growing under phosphate limitation, as doubling the concentration of any of the organic phosphates resulted in a doubling of the equilibrium culture population density. The concentration of organic phosphate was lowered in three of the long-term populations, at generations 415 (population J), 299 (population K), and 693 (population E), maintaining cell density within the range $5 \times 10^{7}-9 \times 10^{7}$, in order to ensure that growth continued to be limited by the concentration of organic phosphate. Cell number was estimated using an electronic particle counter (Celloscope 111, Particle Data Inc. Elmhurst, Ill; or Coulter Counter ZM, Hialeah, Fla), after sonication with a Braunsonic 1510 sonicator and a needle probe to separate clumped cells. Continuous cultures were sampled approximately every 25 generations and an aliquot stored in $40 \%$ glycerol at $-70{ }^{\circ} \mathrm{C}$ for later analysis YEPD medium contained $1 \%$ yeast extract, $2 \%$ bacto-peptone, and $2 \%$ glucose. For solid medium $1.5 \%$ agar was added.

Preparation of chromosomal DNA for pulse-field gel analysis. Stationary-phase cultures $(10 \mathrm{ml})$ were pelleted and washed twice in $50 \mathrm{mM}$ EDTA ( $\mathrm{pH} 7.5$ ). Pellets were resuspended in $2 \mathrm{ml}$ of $50 \mathrm{mM}$ EDTA (pH 7.5) and heated to $37^{\circ} \mathrm{C}$ in a heating block. A $1 \%$ solution of Seakem agarose (FMC Bioproducts, Rockland, ME) in $0.125 \mathrm{M}$ EDTA ( $\mathrm{pH} 7.5$ ) was heated to boiling and cooled to $45^{\circ} \mathrm{C}$. Then $38 \mu$ l of zymolase solution ( $1 \mathrm{M}$ sorbitol, $100 \mathrm{mM}$ sodium citrate, $60 \mathrm{mM}$ EDTA, $0.1 \%$ zymolyase, $0.8 \% \beta$-mercaptoethanol; final $\mathrm{pH} \mathrm{5.6)}$ and $2.5 \mathrm{ml}$ of agarose solution were added to $2 \mathrm{ml}$ of the cell suspension. The agarose-cell mixture was shaken, dispensed into plexiglass slots $(1 \mathrm{~mm} \times 28 \mathrm{~mm} \times 4 \mathrm{~mm})$ to facilitate the formation of the agarose plugs, and allowed to cool. The solidified plugs were extruded from the slots, covered with buffer $(0.5 \mathrm{M}$

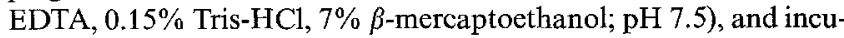
bated at $37^{\circ} \mathrm{C}$ overnight. The overlay was then replaced with NDS buffer $(0.5 \mathrm{M}$ EDTA, pH $8.0,0.15 \%$ Tris- $\mathrm{HCl}, 1 \%$ lauroyl sarcosine; $0.1 \%$ proteinase $\mathrm{K}$ added immediately before use), and the samples incubated at $50^{\circ} \mathrm{C}$ overnight. NDS buffer was removed and replaced with $50 \mathrm{mM}$ EDTA, $\mathrm{pH}$ 8.0. Samples were incubated at $50^{\circ} \mathrm{C}$ for $2-3$ days with four changes of EDTA. Whole chromosomes embedded in agarose were stored in $50 \mathrm{mM}$ EDTA at $4{ }^{\circ} \mathrm{C}$ for up to 1 month (Carle and Olson 1985; Vollrath and Davis 1987).

Chromosome separations. Prepared chromosome samples were cut to fit the wells of a $1 \%$ agarose (Boehringer Mannheim (Indianapolis,
IN) low EEO agarose) gel in $1 \times$ TBE buffer (Maniatis et al., 1982). Chromosomes were separated by the CHEF method of pulse-field gel electrophoresis (Chu et al. 1986) in $0.5 \times$ TBE buffer. The running buffer was recirculated through $4^{\circ} \mathrm{C}$ coolant, resulting in a running temperature of the gel of about of $8^{\circ} \mathrm{C}$. Various combinations of voltage and switching times were used to optimize separation of the different size ranges. The sizes of the smaller chromosomal length variants were estimated by linear interpolation using bacteriophage lambda concatemers (" $\lambda$-ladders") as size markers. Sizes of the larger chromosomal length variants were estimated by linear interpolation using the chromosome bands of CP1AB-1A as size markers. Estimates of the sizes of these chromosomes were obtained from Mortimer and Schild (1985).

DNA manipulations and hybridization procedures. Details of the procedures for preparation of total yeast DNA and probes, and of the procedure for DNA-DNA hybridization have been described previously (Adams and Oeller 1986). Identities of the chromosomespecific hybridization probes are described by Carle and Olson (1985). For one chromosome length variant observed in population $\mathrm{J}$, chromosome assignment could not be made using the chromosome-specific probes. In this case, the chromsome was excised from the gel and the DNA purified using "Geneclean" (Bio 101 Inc., La Jolla, Calif.), following the protocols recommended by the manufacturer. The DNA was then radioactively labelled by the random priming method, using a kit supplied by Boehringer-Mannheim, and used as probe. The $\lambda$-ladders were prepared as described previously (Carle and Olson 1984).

Estimation of copy-number changes in the structural loci for acid phosphatase. The DNA to be analysed was digested either with EcoRI and $C l a \mathrm{I}$ or with PstI restriction endonucleases (Boehringer Mannheim), using protocols suggested by the manufacturer, and the fragments separated by electrophoresis on $0.7 \%$ agarose "submarine" gels (Maniatis et al. 1982). Double digestion with EcoRI/ $\mathrm{Cla}$ I results in a single band containing both the $\mathrm{PHOS}$ and $\mathrm{PHO} 3$ genes, and two more bands each composed of homologous sequences from both $P H O 10$ and $P H O 11$, while digestion with $P_{s t} \mathrm{I}$ allows the four structural genes for acid phosphatase to be resolved into four distinct bands detectable by DNA-DNA hybridization. The acid-phosphatase probes were derived from pAP18 and pAP20, described by Andersen et al. (1983). Due to the homology shared by these genes (Hinnen et al. 1987), it is possible to detect all four loci with any one of the probes under slightly reduced strigency conditions. pAP18 is composed of pBR322 with a $5 \mathrm{~kb}$ EcoRI insert containing the $1401 \mathrm{bp}$ open reading frame of $P H O 11$, plus approximately $1.4 \mathrm{~kb}$ and $2.1 \mathrm{~kb}$ from outside the $5^{\prime}$ and $3^{\prime}$ ends of the gene respectively. pAP20 is composed of pBR322 with an $8 \mathrm{~kb} E c o$ RI insert containing both of the $1401 \mathrm{bp}$ open reading frames from the directly oriented, tightly linked $\mathrm{PHO}$ and $\mathrm{PHO} 3$ genes. Probes were the entire pAP18 plasmid when probing for the $P H O 11$ and $P H O 10$ genes, and a $3.5 \mathrm{~kb} \mathrm{ClaI}$ fragment from pAP20 when probing for PHO5 and PHO3. The $3.5 \mathrm{~kb} C l a \mathrm{I}$ fragment from pAP2O was obtained by elution from agarose gels using Schleicher and Schuell (Keene, NH) NA45 DEAE cellulose paper. This $3.5 \mathrm{~kb}$ ClaI fragment contains both of the $\mathrm{PHO} 5$ and $\mathrm{PHO} 3$ open reading frames, a $451 \mathrm{bp}$ intergenic region separating the two genes, and a total of $319 \mathrm{bp}$ from the extreme ends of the tandem pair. Upon initial examination of the autoradiographs by eye it was apparent that the terminal clones from several of the populations had experienced an increase in copy number of some of the four acid-phosphatase loci. Since each lane of the gels was loaded with approximately the same amount of DNA, between-lane comparisons of hybridization intensities were sufficient to indicate the qualitative differences in copy number. Differences apparent from observation of the conventional gels were also confirmed by visual and/or densitometric analysis of hybridization spectra of pulse-field gels hybridized with the same probes. The relative copy number of each of the acid-phosphatase loci was estimated by first scanning individual lanes of the autoradiographs with a laser densitometer (LKB Ultrascan XL, LKB Produkter AB, Bromma, Sweden). Then, one of the 
acid-phosphatase hybridizing bands which showed no lane-to-lane variability in hybridization intensity, was used as an internal singlecopy standard to which the other acid-phosphatase loci of that lane were compared. The ratio of the hybridization intensities (areas under the curves) of the phosphatase bands within each lane was computed. Control lanes were chosen which showed no apparent copy-number changes of the phosphatase genes in question. The ratios of individual experimental lanes (lanes which had an apparent copy-number change in one of the acid-phosphatase loci) were then divided by the mean ratio from the control lanes. This resulted in individual estimates of the relative copy number of the strains from a given population. These individual estimates were then pooled, and the mean relative copy number of the phosphatase locus from a given population was calculated. In the case of the clones isolated from population $\mathrm{B}$, laser densitometry data from both conventional and pulse-field gels were combined to compute the relative $P H O 10$ copy number.

\section{Results}

Thirteen separate populations of haploid $a$ and diploid $a / \alpha$ populations of $S$. cerevisiae, initiated with single clones, were maintained in continuous culture for up to 1000 generations with growth limited by the concentration of one or more organic phosphates. Details of these populations and the environments in which they were grown are given in Table 1 . We have previously shown that under similar conditions, population replacements occur about every 50 generations, where the predominating clone in the population is replaced by one with a greater level of adaptation to the environment (Paquin and Adams 1983). Substantial increases in equilibrium density, in the in-vivo activity of acid phosphatase, as well as changes in other physiological parameters (see Adams

Table 1. Description of long-term populations

\begin{tabular}{|c|c|c|c|c|c|}
\hline $\begin{array}{l}\text { Popu- } \\
\text { lation }^{2}\end{array}$ & $\begin{array}{l}\text { Inoculating } \\
\text { (ploidy) } \\
\text { strain }\end{array}$ & Ploidy & $\begin{array}{l}\text { Limiting } \\
\text { phosphate } \\
\text { source }^{b}\end{array}$ & $\begin{array}{l}\text { Environ- } \\
\text { mental } \\
\text { character- } \\
\text { istics }\end{array}$ & $\begin{array}{l}\text { Gener- } \\
\text { ations } \\
\text { elapsed }\end{array}$ \\
\hline $\mathrm{E}$ & CP1AB-1A & Haploid & UMP & Constant & 770 \\
\hline $\mathrm{F}$ & CP1AB-1A & Haploid & G1P & Constant & 711 \\
\hline $\mathrm{G}$ & CP1AB-1A & Haploid & PGA & Constant & 1069 \\
\hline $\mathrm{J}$ & CP1AB-1A & Haploid & $\beta \mathrm{GP}$ & Constant & 1001 \\
\hline $\mathrm{K}$ & CP1AB-1A & Haploid & G6P & Constant & 1024 \\
\hline $\mathrm{C}$ & CP1AB-1A & Haploid & $\beta \mathrm{GP}+\mathrm{UMP}$ & Constant & 763 \\
\hline A & CP1AB-1A & Haploid & $\beta \mathrm{GP}+\mathrm{UMP}$ & Varying & 1003 \\
\hline $\mathrm{N}$ & $\mathrm{PO} 43$ & $\mathrm{Ha}$ & $\beta \mathrm{GP}+\mathrm{PGA}$ & Cor & 68 \\
\hline $\mathrm{L}$ & PO43-283B & Haploid & $\beta \mathrm{GP}+\mathrm{PGA}$ & Varying & 991 \\
\hline $\mathrm{D}$ & CP1A & $\mathrm{D}$ & $\beta \mathrm{GP}+\mathrm{UMP}$ & Const & 752 \\
\hline M & CP1AB & Diploid & $\beta \mathrm{GP}+\mathrm{PGA}$ & Constant & 981 \\
\hline B & $\mathrm{C}$ & $\mathrm{D}$ & $\beta \mathrm{GP}+\mathrm{UMP}$ & Var & 668 \\
\hline $\mathrm{H}$ & CP1AB & Diploid & $\beta \mathrm{GP}+\mathrm{PGA}$ & Varying & 1017 \\
\hline
\end{tabular}

a Varying environments: experiments $\mathrm{A}$ and $\mathrm{B}$, phosphate sources were alternated every $24 \mathrm{~h}$ (approximately six generations); experiments $L$ and $H$, phosphate sources were alternated every $48 \mathrm{~h}$ (approximately 12 generations)

b Phosphate sources: UMP, Uridine-5'-phosphate' G1P, Glucose1-phosphate; PGA, phosphoglyceric acid" $\beta \mathrm{GP}, \beta$-glycerol phosphate; G6P, Glucose-6-phosphate et al. 1985), indicated that genetic adaptation to the environment had occurred. To determine the importance of major chromosomal changes, the electrophoretic karyotype of at least ten independent clones isolated at the termination of each population was examined. Chromosome identification of the bands was made by DNADNA hybridization with chromosome-specific probes. Chromosomes with variant mobilities on pulse-field gels were in most cases interpreted as possessing simple translocations, duplications and deletions. However, since a limited number of chromosome-specific probes were used, we cannot exclude the possibility that a more complicated pattern of chromosome rearrangement had occurred involving in each case more than one translocation, deletion, and duplication event.

The results shown in Table 2 (see also Fig. 1) indicate that a surprising number of large-scale rearrangements have occurred during the process of adaptation in nine out of the 13 populations, and that these rearrangements involve eight of the 15 chromosomes, not including chromosome XII. As many as nine of the 13 populations also contained length variants for chromosome XII. However, we were not consistently able to resolve these chromosome XII variants (see also Carle and Olson 1985). Since the size of this chromosome also varies among different isolates of the same strain (Link and Olson 1991), data on sizes of these putative variants and their frequency in the populations are not included in Table 2.

Two main categories of chromosomal rearrangement were observed: (1) deletions, and (2) accretions in size, including putative tandem and non-tandem duplications. Accretions in chromosome size were observed in both haploid and diploid populations, and involved size increases of as much as $390 \mathrm{~kb}$. Chromosome identification of the variant bands was made by DNA-DNA hybridization either using chromosome-specific probes, or probes of DNA prepared from entire chromosomes. The chromosomal origin of the accretions in size is, therefore, in most cases undetermined, and many derive from the same or different chromosomes.

A particularly notable chromosome-length variant, approximately $1100 \mathrm{~kb}$ in size, was observed in population J. DNA-DNA hybridizations indicated that this chromosome band was comprised of sequences homologous to both chromosome II and XVI, and contained sequences homologous to the $\mathrm{PHO} / \mathrm{PHO}$ loci, yet did not contain sequences homologous to the LYS2 locus also located on chromosome II, 14 centiMorgans distal to the acid phosphatase loci PHO3/PHO5, or to $G A L 4$ located close to one of the telomeres of chromosome XVI (data not shown). This "new" chromosome is, therefore, different in structure from the duplication observed by Hansche et al. (1978; and see below) which involved translocation of the right arm of chromosome II to chromosome XVI (therefore including the LYS2 locus).

Table 2 also shows that the terminal samples isolated from five of the 13 populations were polymorphic for chromosomal rearrangements. Some of these polymorphisms may be expected to be transient, a result of assaying the populations during a changeover where one clone is being replaced by another. However, it is also possible 


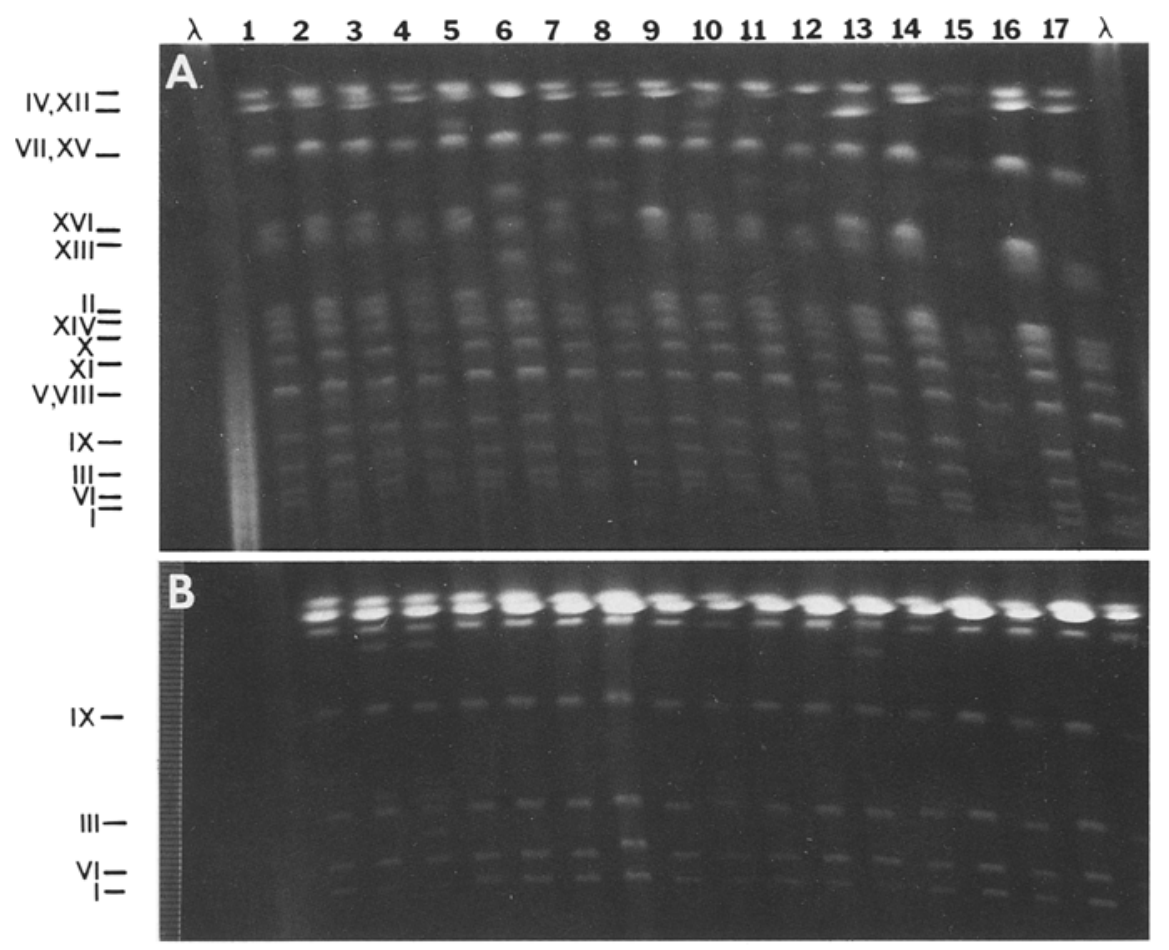

Fig. 1A, B. Pulse-field gel electrophoresis of selected clones isolated at the termination of long-term continuous cultures, showing chromosomal length variants as well as changes in chromosome number. A 1\% agarose gel run at $3.08 \mathrm{v} / \mathrm{cm}$ for $20 \mathrm{~h}$, followed by $3.27 \mathrm{v} / \mathrm{cm}$ for $47 \mathrm{~h}$ with a switching interval of $210 \mathrm{~s}$ throughout the entire period. Under our conditions, these parameters provided the best resolution of size variants for the medium-sized chromosomes. B $1 \%$ agarose gel run at $4.27 \mathrm{v} / \mathrm{cm}$ for $44 \mathrm{~h}$ with a switching interval of $60 \mathrm{~s}$. Under our conditions, these parameters provided the best resolution of size variants for the smaller-sized chromosomes. Lanes: 1, CP1AB-1; 2 and 3, independent clones isolated from the terminal sample taken at generation 668 of population $\mathrm{B} ; 4$ and 5 , independent clones isolated from the terminal sample taken at gen-

that a fraction of the polymorphisms are stable or quasistable in the populations for long periods of time. We therefore assayed samples taken from the most polymorphic population, E, at intermediate generations to determine the dynamics of the polymorphisms. All four variants in the sizes of chromosomes II and XVI, described in Table 2 for population $E$, were first detected at generation 529. Thus, the E population was polymorphic over the course of at least 261 generations, a result which argues strongly against these polymorphisms being transient.

Hansche et al. (1978) have shown that prolonged growth under organic-phosphate limitation may result in the non-tandem duplication of the fragment of chromosome II carrying the major gene for acid phosphatase (PHO5). It may, therefore, be expected that increases in the copy number of the structural genes for acid phosphatase may also be selected under our conditions. Accordingly, we searched for increases in copy number by densitometric scaning of autoradiographs obtained by hybridizing radioactively-labelled probes specific for the acid-phosphatase structural loci, to total DNA preparations from clones isolated from each of the 13 populations. eration 752 of population $\mathrm{D} ; 6$ and 7 , independent clones isolated from the terminal taken at generation 770 of population $\mathrm{E} ; 8$, clone isolated from the terminal sample taken at generation 711 of population F; 9, PO43-283B; 10 , clone isolated from the terminal sample taken at generation 1017 of population $\mathrm{H} ; 11$ and 12 , independent clones isolated from the terminal sample taken at generation 1001 of population $\mathrm{J} ; 13$, sample unrelated to this communication; 14 , clone isolated from the terminal sample taken at generation 991 of population $\mathrm{L} ; 15$, clone isolated from the terminal sample taken at generation 981 of population $\mathrm{M}$; 16 , clone isolated from the terminal sample taken at generation 681 of population N. $\lambda$, bacteriophage lambda concatemers (" $\lambda$-ladders") used as size markers for the smaller-sized chromosome variants (seen only in Fig. 1 A)

Three structural genes of inducible acid phosphatase have been identified; $P H O 5, P H O 10$ and $P H O 11$, located on chromosome III, VIII and I respectively. In addition, a constitutively expressed $P H O 3$ structural locus is located $451 \mathrm{bp} 3^{\prime}$ to the PHO5 gene in direct orientation. Using specific probes (see Materials and methods) and published restriction maps for these loci (Andersen et al. 1983; Venter and Horz 1989; de Steensma et al. 1989), we carried out conventional DNA-DNA hybridization experiments on at least four individual clones from the terminal samples taken from each of the 13 populations. Figure 2 shows the hybridization spectra for clones derived from populations $\mathrm{H}, \mathrm{J}$ and $\mathrm{K}$. It can be seen that hybridization to bands containing the PHO5 and PHO1O loci is markedly more intense for the clones isolated from population J. Quantitative measures of hybridization intensity for the four inducible acid-phosphatase loci were obtained by laser densitometry for all populations, and the copy numbers of the different loci estimated. The results (Table 3) show significant changes in copy number for one or more of the structural acid-phosphatase loci, PHO3/PHO5 and $P H O 10$, in four of the 13 populations. No change in the copy number of the PHO11 locus was seen. Interestingly, population $\mathrm{E}$ showed no significant 
Table 2. Chromosomal changes observed

\begin{tabular}{ccc}
\hline $\begin{array}{l}\text { Pop- } \\
\text { ulation }\end{array}$ & Ploidy & $\begin{array}{r}\text { Frequ } \\
\text { in pop } \\
\text { ulation }\end{array}$ \\
\hline $\begin{array}{c}\text { A. Deletions } \\
\text { J }\end{array}$ & Haploid & 0.05 \\
D & Diploid & 0.2 \\
B & Diploid & 0.20 \\
B & Diploid & 0.4 \\
B. Accretions & \\
E & Haploid & 0.22 \\
E & Haploid & 0.22 \\
E & Haploid & 0.09 \\
E & Haploid & 0.27 \\
F & Haploid & 1.0 \\
F & Haploid & 1.0 \\
J & Haploid & 1.0
\end{tabular}

$\begin{array}{lll}\text { L } & \text { Haploid } & 1.0 \\ \text { N } & \text { Haploid } & 1.0 \\ \text { D } & \text { Diploid } & 0.3 \\ & & \\ \text { D } & \text { Diploid } & 0.6 \\ & & \\ \text { B } & \text { Diploid } & 0.5 \\ & & \\ \text { H } & \text { Diploid } & 0.36\end{array}$

Aneuploid containing an extra copy of Chr. $\mathrm{V}$ with a deletion approximately $50 \mathrm{~kb}$ in size Heterozygous for an approximately $50 \mathrm{~kb}$ deletion of Chr. XI Heterozygous for an approximately $40 \mathrm{~kb}$ deletion in Chr. III Heterozygous for an approximately $30 \mathrm{~kb}$ deletion of Chr.V

An approximately $10 \mathrm{~kb}$ accretion in size of Chr. II

An approximately $20 \mathrm{~kb}$ accretion in size of Chr. II

An approximately $50 \mathrm{~kb}$ accretion in size of Chr. XVI

An approximately $20 \mathrm{~kb}$ accretion in size of Chr. XVI

An approximately $250 \mathrm{~kb}$ accretion in size of Chr. II

An approximately $60 \mathrm{~kb}$ accretion in size of Chr. XIII

Aneuploid containing an extra chromosome with sequences homologous to chromosomes II and XVI. Total size approximately $1100 \mathrm{~kb}^{\mathrm{a}}$

An approximately $10 \mathrm{~kb}$ accretion in the size of Chr. XI

An approximately $10 \mathrm{~kb}$ accretion in the size of Chr. XI

Heterozygous for an approximately $10 \mathrm{~kb}$ accretion in size of Chr. II

Heterozygous for an approximately $390 \mathrm{~kb}$ accretion in size of Chr. XIV

Heterozygous for an approximately $140 \mathrm{~kb}$ accretion in size of Chr. I

Heterozygous for an approximately $390 \mathrm{~kb}$ accretion in size of Chr. XIV

a The chromosome-specific probes $L Y S 2$ (II) and GAL4 (XVI) did not hybridize to this chromosome, indicating that it contained only partial sequences of both chromosomes

change in the copy number of $\mathrm{PHO} / \mathrm{PHO} 5$ (or any other acid-phosphatase locus) in spite of the fact that increases in the size of chromosome II, on which the PHO3/PHO5 loci are located, were detected in this population.

\section{Discussion}

The results described in this paper document the occurrence of large-scale chromosome rearrangements in haploid and diploid populations of $S$. cerevisiae in environments where growth is limited by the concentration of organic phosphate. Three aspects of the results deserve further comment.
Table 3. Correlation between changes involving the chromosomes carrying the structural loci for acid phosphatase, and changes in the copy number of those loci. Note: all other populations showed no changes in copy number for these loci

\begin{tabular}{|c|c|c|c|c|c|c|}
\hline \multirow[t]{2}{*}{$\begin{array}{l}\text { Popu- } \\
\text { lation }\end{array}$} & \multicolumn{3}{|c|}{$\begin{array}{l}\text { Changes in } \\
\text { chromosome }\end{array}$} & \multicolumn{3}{|c|}{ Copy number $\pm \mathrm{SD}$} \\
\hline & I & II & VIII & PHO11 & $\begin{array}{l}\text { PHO3/ } \\
\text { PHO5 }\end{array}$ & PHO10 \\
\hline$B^{a}$ & + & - & - & $1.00 \pm 0.20$ & $1.05 \pm 0.18$ & $2.17 \pm 0.42$ \\
\hline$E^{b}$ & - & + & - & $1.00 \pm 0.04$ & $0.80 \pm 0.08$ & $1.03 \pm 0.05$ \\
\hline$F$ & - & + & - & $1.00 \pm 0.31$ & $3.30 \pm 0.83$ & $1.20 \pm 0.29$ \\
\hline G & - & - & - & $1.00 \pm 0.21$ & $1.00 \pm 0.25$ & $7.4-11.4^{\mathrm{c}}$ \\
\hline $\mathbf{J}$ & - & + & - & $1.00 \pm 0.12$ & $4.33 \pm 0.60$ & $3.29 \pm 0.43$ \\
\hline
\end{tabular}

a The terminal sample isolated from the $B$ population was polymorphic for an increase in the size of chromosome I. None of the clones assayed, whether possessing the chromosome length variant or not, showed a change in copy number of PHO11 located on this chromosome. However, all clones showed an increase in the copy number of PHO10, located on chromosome VIII, for which no chromosome length variants were detected

$\mathrm{b}$ The terminal sample isolated from the E population was polymorphic for two chromosome changes involving chromosome II. None of the clones assayed, whether possessing the chromosome length variant or not, showed a change in the copy number for any of the three loci

c The terminal sample isolated from the $G$ population was polymorphic for the location of copies of the PHO1O locus. All clones isolated from this sample showed that it was absent from chromosome VIII, and different clones showed the location of this locus on chromosome XI, chromosome XVI, or chromosome VII/XV. Since chromosomes VII and XV co-migrate in our strains, the locus of $P H O 10$-homologous sequences could not be assigned unambiguously for such clones

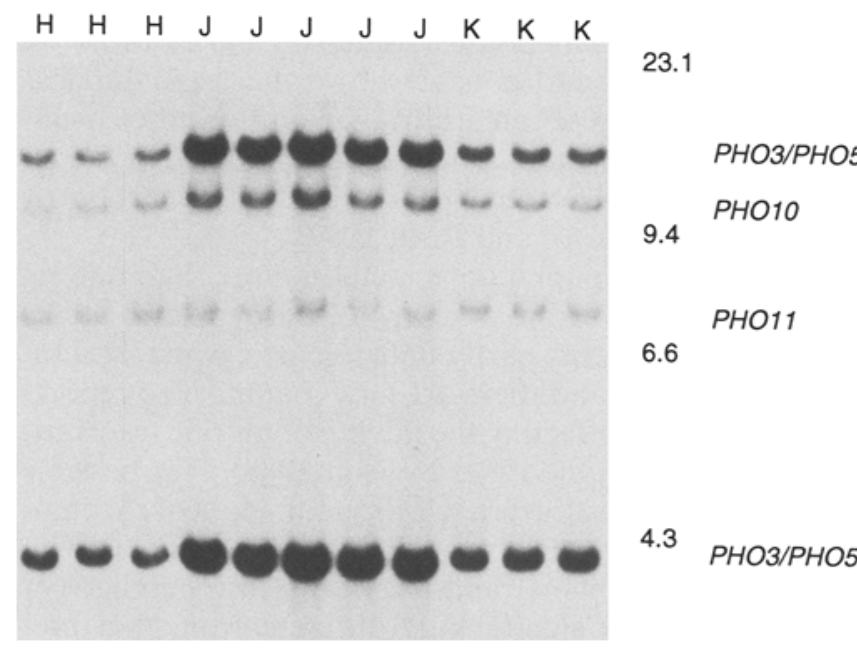

Fig. 2. DNA-DNA hybridization spectra of terminal clones from populations $\mathrm{H}$, J and $\mathrm{K}$. Total DNA preparation were digested with Pst I and the blot was probed with the $3.5 \mathrm{~kb}$ fragment from pAP20 (see Materials and methods). The sizes (kb) and corresponding acid-phosphatase gene homologies are shown to the right of the autoradiograph. In this blot, densitometric scans of $\mathrm{H}$ and $\mathrm{K}$ clones were used as controls to confirm the relative increase in copy number observed for the $\mathrm{PHO} 10$ and $\mathrm{PHO} / \mathrm{PHO}$ loci in the clones derived from the $J$ population (see Table 3 and Materials and methods) 


\section{Frequency and number of chromosomal rearrangements}

The variety of chromosomal rearrangements that have occurred indicates that the genome of $S$. cerevisiae is surprisingly labile, though probably not more so than those of prokaryote species (see Riley 1985). Seventeen (exclusive of changes in size of chromosome XII) different chromosome rearrangements were observed in eight of the 13 populations. The range of different chromosomelength variants seen is particularly striking, given the similarity of the environments in which the 13 populations were grown. In all cases, growth was limited by the concentration of organic phosphates, in medium buffered at $\mathrm{pH}$ 6. The results show that two broad classes of rearrangements attain significant frequencies during adaption to limiting concentrations of organic phosphate: (1) deletions, and (2) tandem and non-tandem duplications. Both classes may also occur in association with an increase in chromosome number. Thus, a variant observed in population $\mathrm{J}$ after 1000 generations possessed an extra copy of chromosome $\mathrm{V}$ containing an approximately $50 \mathrm{~kb}$ deletion. Still other classes of rearrangements, such as inversions may also attain high frequencies but would not be detected by pulse-field electrophoresis.

Four independent chromosome-length variants that resulted from loss of chromosomal material were identified in the terminal samples from three populations. In all cases, the clones identified were heterozygous for the deletions, and no clones were seen that had suffered a loss of unique chromosome segments. Since the size of the deletions, approximately $30-50 \mathrm{~kb}$, was appreciable, it is likely that such cells would be strongly selected against, or even be inviable due to the loss or attenuation of essential cellular functions, if the cells were not aneuploid.

Gene duplications have been found to occur at a high frequency in S. typhimurium (Anderson and Roth 1977), and a number of studies have shown that gene duplications are typically selected during evolution in environments where growth is limited by enzyme activity (e.g., Rigby et al. 1974) or by the availability of carbon or energy sources (Sonti and Roth 1989).

Several of the populations contain more than one rearrangement. Since the stability of chromosomal rearrangements is at least partly under genetic control (Hansche et al. 1978), and there are now a number of reports that identify loci affecting the fidelity of mitotic transmission (Kouprina et al. 1988; Newlon 1988), it is possible that adaptation resulted in selection for a loss of chromosome stability. However, the distribution of chromosomal rearrangements is random, in that the number per population is not significantly different from that predicted by the Poisson distribution, indicating that there is no evidence that adaptation had resulted in genetic differences for chromosome stability (data not shown) among the populations.

The high frequencies of such chromosomal rearrangements that are attained after adaptation over approximately 1000 generations may be explained by either assuming that they confer a direct selective advantage on the cells carrying them, or alternatively by assuming that they are not selectively favored but are linked to independent, selectively favorable, mutations not contained within the chromosomal rearrangement ("hitch-hiking"; Maynard Smith and Haigh 1974). Although we cannot unequivocally eliminate this alternative "hitch-hiking" hypothesis, four considerations make it extremely unlikely:

(1) The "hitch-hiking" hypothesis would require that the frequency of chromosomal rearrangements is sufficiently high to give a reasonable probability of a chromosomal rearrangement occurring in a clone carrying an adaptive mutation. All the accumulated evidence from the genetics and molecular biology of yeast indicates that the rate of occurrence of chromosomal rearrangements is at least as low as, or lower than, the rate of "conventional" mutation. In two independent studies, only approximately $10 \%$ of interchromosomal gene conversion events were accompanied by reciprocal exchanges, detected as translocations or transpositions (Mikus and Petes 1982; Sugawara and Szostak 1983). Furthermore, amplifications and duplications, which may result in accretions in size, have been estimated to occur at extremely low rates; $1 \times 10^{-11}-1 \times 10^{-12} / \mathrm{mitosis}$ (Hansche et al. 1978; Paquin et al. 1992). To explain, non-selectively, the prevalence of the chromosomal rearrangements seen in the populations described here, the rate of production of chromosomal variants would have to be several orders of magnitude higher than the mutation rate.

(2) Some of the rearrangements do involve a change in the copy number of the structural genes for acid phosphatase, and there is good evidence that relative fitness is directly related to the activity of this enzyme in an organic-phosphate-limited environment (Francis and Hansche 1972, 1973).

(3) The magnitude of the accretions and deletions in chromosome size are large, ranging from less than $10 \mathrm{~kb}$ to $390 \mathrm{~kb}$. Thus, each rearrangement generates copynumber changes for a large number of loci. It is unlikely that changes of this magnitude can be selectively neutral. (4) Finally, the maintenance of chromosome-length polymorphisms for long periods in one population that was highly polymorphic, suggests that they are not transient but rather that they are selectively maintained, most likely by interactions between the different variants (cf., Helling et al. 1987). A non-selective explanation for the presence of polymorphisms would predict that the duration of the polymorphisms would be short, being determined by the rate of population replacements caused by the appearance and predominance of adaptive mutations (e.g., see Kubitschek 1974). The results of Paquin and Adams (1983) indicate that population replacements occur about every 50 generations.

\section{Changes involving the structural loci for acid phosphatase}

Previous results (Francis and Hansche 1972, 1973) have shown that growth, and therefore fitness, is directly related to the activity of the extracellular-enzyme acid phosphatase, in populations maintained in organic-phosphatase-limited environments at high $\mathrm{pH}$. Furthermore, Hansche and co-workers (Hansche 1975; Hansche et al. 
1978) have shown that prolonged growth under limiting concentration of two different organic phosphates, $\beta$ glycerol phosphate and uridine-monophosphate (equivalent to the environments of populations $E$ and $J$ ), can result in the selection of duplications of the right arm of chromosome II (containing the loci PHO3/PHO5). However, only a small minority $(2 />17)$ of the chromosomelength modifications described in Table 2 involved changes in the copy number of the structural loci for acid phosphatase.

Changes in the copy number of the structural genes for acid phosphatase were seen in four of the 13 populations; in two populations the copy number of the $P H O 3 / P H O 5$ loci had increased whereas in three of the populations the copy number of the PHO10 locus had increased. A surprising feature of these results is that changes in the copy number of the acid-phosphatase structural loci are implicated in only two ( $\mathrm{F}$ and $\mathrm{J}$ ) of the five populations in which chromosome-length modifications involving the chromosome (I, II and VIII) bearing these genes were detected. For example, population B contains an accretion in the size of chromosome $\mathrm{I}$, yet this does not involve an increase in the copy number of the PHO11 locus. In the case of the clones isolated from the terminal sample taken from population $G$, no detectable changes were observed in the electrophoretic karyotypes, yet the copy number of the $P H O 10$ locus had increased dramatically (see Table 3). In each of these clones, the PHO10 gene was deleted from its normal position on chromosome VIII and the amplified copies were translocated to other chromosomes. Three different variants were identified in this sample, with the PHO1O locus translocated to chromosome XI, chromosome XVI, or chromosome VII or $X V$. (Since chromosomes VII and XV co-migrate in these strains, unambiguous determination of the locus of PHO10 was not possible in such clones). Thus, the data indicate that population $G$ was polymorphic for the location of PHO1O. The analysis of the changes in copy numbers of the acid-phosphatase structural loci in this population will be the subject of a future communication.

\section{Population polymorphism}

A number of the populations surveyed were polymorphic for the observed chromosomal rearrangements. This is at variance with the classical model of evolution in asexual populations originally proposed by Muller (1932; see alow Crow and Kimura 1965) which asserts that populations will be virtually monomorphic except for those periods when one clone is replaced by another of higher fitness (cf. Kaplan et al. 1989; Maruyama and Birky 1991). Several recent reports have also identified polymorphic populations which are stable. Thus, Helling et al. (1987) have described a stable polymorphism maintained in a simple environment where growth was limited by the concentration of glucose. In addition, the duplications observed by Sonti and Roth (1989) did not become fixed in the population, in spite of their selective advantage. Finally, we (Rosenzweig and Adams, in preparation) have observed polymorphisms arising in glucose-limited long-term populations of $S$. cerevisiae, which may be stably maintained.
Acknowledgements. We thank P. E. Hansche for strains 507 and 512, M. Olson and L. Riles for the gift of the chromosome-specific probes described in Carle and Olson (1985), S. A. Parent, M. Grunstein, R. Kramer and A. Hinnen for the gift of the probes for PHO3/PHOS and PHO1O and PHO11, and R. F. Rosenzweig for helpful discussion. This work was supported in part by the National Institutes of Health grant GM30959.

\section{References}

Adams J, Hansche PE (1974) Genetics 76:327-338

Adams J, Oeller PW (1986) Proc Natl Acad Sci USA 83:7124-7127 Adams J, Paquin C, Oeller PW, Lee LW (1985) Genetics 110: 173-185 Andersen N, Thill GP, Kramer RA (1983) Mol Cell Biol 3: 562-569 Anderson RP, Roth JR (1977) Annu Rev Microbiol 31:473-505 Carle GF, Olson MV (1984) Nucleic Acids Rev 12:5647-5664 Carle GF, Olson MV (1985) Proc Natl Acad Sci USA 82:3756-3760 Chu G, Vollrath D, Davis RW (1986) Science 234: 1582-1585

Crow JF, Kimura M (1965) Amer Nat 99:439-450

Francis JC, Hansche PE (1972) Genetics 70:59-73

Francis JC, Hansche PE (1973) Genetics 74:259-265

Hansche PE (1975) Genetics 79:661-674

Hansche PE, Beres V, Lange P (1978) Genetics 88:673-687

Helling RB, Vargas CN, Adams J (1987) Genetics 116:349-358

Hinnen A, Bajwa W, Meyhack B, Rudolph H (1987) Molecular aspects of acid phosphatase synthesis in Saccharomyces cerevisiae. In: Torriani-Gorini A, Rothmann FG, Silver S, Wright A, Yagil E (eds) Phosphate metabolism and cellular regulation in microorganisms. American Society for Microbiology, Washington DC, pp 56-62

Kaplan NL, Hudson RR, Langley CH (1989) Genetics 123: 887-889 Kouprina NY, Pasina OB, Nikolaishwili NT, Tsouladze AM, Larionov VL (1988) Yeast 4:257-269

Krawiec S, Riley M (1990) Microbiol Rev 54:502-539

Kubitschek HE (1974) Symp Soc Gen Microbiol 24: 105-130

Link AJ, Olson MV (1991) Genetics 127:681-698

Maniatis T, Fritsch EF, Sambrook, J (1982) Molecular cloning - a laboratory manual. Cold Spring Harbor Laboratory Press, Cold Spring Harbor, New York

Maruyama T, Birky CW Jr (1991) Genetics 127:449-451

Maynard Smith J, Haigh J (1974) Genet Res 23:25-35

Mikus MD, Petes TD (1982) Genetics 101:369-404

Mortimer RK, Schild D (1985) Microbiol Rev 49:181-212

Muller HJ (1932) Amer Nat 68:118-138

Newlon CS (1988) Microbiol Rev 52:568-601

O'Brien SJ, Seuanez HN, Womack JE (1988) Annu Rev Genet 22:323-351

Ornston LN, Neidle EL, Houghton JE (1990) Gene rearrangements, a force for evolutionary change; DNA sequence rearrangements, a source of genetic constancy (1990) In: Drlica K, Riley M (eds) The Bacterial chromosome. ASM Publications, Washington D.C. pp 325-333

Paquin C, Adams J (1982) Curr Genet 6:21-24

Paquin CE, Adams J (1983) Nature 302: 495-500

Paquin CE, Dorsey M, Crable S, Sprinkel M, Sondej M, Williamson VM (1992) Genetics 130:263-271

Petes PD, Hill CW (1988) Annu Rev Genet 22:147-168

Rigby PWJ, Burleigh BD, Hartley BS (1974) Nature 251:200-204

Riley M (1984) Arrangement and rearrangement of bacterial genomes. In: Mortlock, RP (ed) Microorganisms as model systems for studying evolution. Plenum Press, New York, pp 285-316

Riley M (1985) Discontinuous processes in the evolution of the bacterial genome. In: Hecht, MK, Wallace, B and Prance, G (eds) Evolutionary Biology. Plenum Press, New York, pp 1-36

Sonti RV, Roth JR (1989) Genetics 123:19-28

Steensma HY de, Jonge P de, Kaptein A, Kaback DB (1989) Curr Genet 16:131-137

Sugawara N, Szostak JW (1983) Proc Natl Acad Sci USA 80:56755679

Venter U, Horz W (1989) Nucleic Acids Res 17:1353-1369

Vollrath D, Davis RW (1987) Nucleic Acids Res 15:7865-7876

Communicated by C. W. Birky, Jr. 